\title{
IDENTIFYING FACTORS AFFECTING OF COOPERATION MANAGEMENT BETWEEN CHARITIES AND THE TEACHING HOSPITALS OF SHAHID BEHESHTI UNIVERSITY OF MEDICAL SCIENCES
}

\author{
Seyed Mahmud Nayeri', Somayeh Hessam², Amir Ashkan Nasiripour ${ }^{3}$, Katayoun \\ Jahangiri4
}

1\&3. Department of Health Services A dministration, Science and Research Branch, Islamic Azad University, Tehran, Iran.

2. Department of Health Services Administration, South Tehran Branch, Islamic Azad University, Tehran, Iran

4. Department of Health in Emergencies and Disasters, School of Public Health and Safety, Shahid Beheshti University of Medical Sciences, Tehran, Iran.

Correspondence:somayehh59@yahoo.com

\begin{abstract}
OBJECTIVES:

One of the mostimportant issues in the provision of health services in every country is providing the necessary resources for presenting these services. Cooperation between charity organizations and public hospitals is especially important as it can increase charity participation, facilitate public participation in the treatment area and develop hospital units. This study aimed was to identify factors affecting of cooperation management between charities and the teaching hospitals of Shahid Beheshti University of Medical Sciences.
\end{abstract}

\section{METHODS:}

This applied, and analytical study was conducted in hospitals of Shahid Beheshti University of Medical Sciences in 2019. The statistical population consisted of 411 people including managers, chiefs and deputies, contracting hospital experts and social workers, managers and lawyers of the university, trustees and managers and charity experts. The research sample consisted of 330 people who were selected through the stratifie drandom sampling method. Data was collected using a researcher-made questionnaire. The SPSS 18 and AMOS software were used to analyze the data.

RESULTS:

The most effective contract pattern determinant had a path coefficient of 1.177, while a least effective current consumption expenditure determinant had the path coefficient of 0.530 .

\section{CONCLUSION:}

The following steps are ways in which costs related to an inpatient department are guaranteed to be covered by a charity during the term of the contract: defining the criteria for selecting a charity to operate in a hospital, choosing a cooperative method and a contract template, determining the share of capital and current costs, and selecting the department type in the contract.

\section{KEYWORDS}

Cooperation Management, Contract Pattern, Charity, Teaching Hospitals. 
In today's world, it is very difficult to have a dynamic and growing society without an efficient health system. While health systems in both developed and developing countries struggle to provide health services in the face of scarcity of resources, physicians and patients demand newer technology and equipment for more accurate and rapid diagnoses. [1-3] this has significantly increased the cost of health care services, especially hospital care services. Since resources allocated to the health sector in most countries do not meet most of the existing needs, countries around the world seek to expand their health system funds so as to ensure that all citizens have access to health services. [4] Charities can be very efficient because of their inherent abilities if they manage scientifically and follow their instructions properly.[5] Non-governmental organizations and charities can help governments and the growth of nations efficiently in various fields and can play a major role in the country and in international relation. [3]

In all countries, charities should be considered the first spontaneous and effective support institutions in the process of poverty alleviation and social harm. In New Jersey, teaching hospitals of members of AAMC provide $35 \%$ of the country's total hospital charitable care. [6] Also at the Mayo Clinic, which has been established in 1889 and is one of the most prestigious educational and medical centers educational and medical centers in the world, providing charitable care is only one part of the charitable duties of this center. [7] Charities in Iran, also have a long history that can be considered at the same time as the formation of social nuclei and family population units. In the database of the Social Deputy of the Ministry of Health until 2018, 814 health charities have been identified, of which about 407 charitable medical centers, 37 charitable hospitals, and 370 health charitable clinics operate throughout the country, and until 2019, there were independent representatives of the health donors association in 56 the university and faculty. Research has shown that in Iran, the main contribution of donors and charities is in the field of hospital construction and their participation in the current costs of hospitals and medical centers is less. [8] By the end of 2019, 2,800 joint projects between donors and charities, the ministry of health, and the governorates have been put into operation that with a value of 72,000 billion Rials.[8]
According to the Harton survey, approximately $75 \%$ of the world's population wants transparency in managing nonprofit organizations. Public trust is considered to be one of the most important and vital factors for the development and attraction of charities in charity.[9] Considering the importance of public participation in promoting the society health, and given that public assistance has recently played an important role in providing health services to people, especially at the university hospitals, it is necessary to establish a charity next to each public hospital in order to support that hospital, increase the role of charities, facilitate public participation in the field of treatment and welfare of patients and develop hospital units. [10] Concerning charities, harms and important issues must be identified and prioritized while regulating the relationship between the governmental and non-governmental sections. [1 1 -12]

The health system reform plan emphasizes organizing the participation of health charities. It also states that the intervention of charities in the health service system as well as in the educational, research and student system, the exchange of legal agreements with provincial health charities under the high supervision of the coordinating unit at the national level and the legal registration of these agreements and their Rial figures in the national budget seem necessary.[10,13] Therefore, for greater productivity, it is better to develop the joint activities of the governmental and non-governmental sectors in order to use the public capacities.[1, 11]

What is certain is that NGOs continue to work as spontaneous and organized forces, whether the public sector agrees or not. For greater productivity of governmental and non-governmental sectors, it is better to use these public capacities with the aim of sustaining developmental goals of effective interactions between these two sectors and to design and implement a model of interaction between governments and the health sector with the related factors. [2]

The government must take steps to coordinate the activities of charities with ministries and universities and to prevent the loss of resources to coordinate the activities of health charities and other components of the health system. [9-12] 
Therefore, the aim of the present study was to identify factors affecting of cooperation management between charities and the teaching hospitals of Shahid Beheshti University of Medical Sciences.

\section{METHODS}

This is an applied, analytical study, conducted in hospitals of Shahid Beheshti University of Medical Sciences.

The present study was carried out in two phases. (Figure 1) The first phase was a library study and a literature review. Data was collected from a series of references including databases, reference books, reports published by the World Health Organization, universities and research centers, lectures and articles presented at scientific conferences, articles published in the last 10 years, valid quarterlies and publications, documents and information banks such as Medline, PubMed, Elsevier and other sites related to the Ministry of Health, charity organizations, and other authorities including governmental and nongovernmental organizations and theses available at the National Library, Shahid Beheshti University of Medical Sciences and Islamic Azad University (Science and Research Unit).

Then, comparative tables were used to analyze the collected data. Similarity and difference points were shown in the comparative table. A researcher-made questionnaire was designed according to the comparative tables, the world health report 2000 and Chiesa model [1 415]. The researcher-made questionnaire in six dimensions (the selection of supporting organizations, different ways of attracting cooperation, determination of the contract pattern, the share of current and consumption expenditures, determination of capital expenditures, and the selection of hospitalization sections) was designed.

In the second phase of the research, the researcher-made questionnaire was given to 20 experts to validate. Among the experts were hospital managers, authorities from Shahid Beheshti University of Medical Sciences and charity institutions; All experts had Ph.D. and M.A. degrees in the fields of either health and management, contract affairs and charity. Using the opinions of experts in these areas, important items within the scope of research were included and other items were excluded in the researchermade questionnaire. The face and content validity of the questionnaire was confirmed in two phases. The first phase was performed using the Delphi method and the second phase was of content type. In the face validity approach of this questionnaire, it was asked whether the appearance of the questionnaire was designed to evaluate the intended purpose or not. Spelling and grammatical errors are also controlled in this section. In content validity, the content validity ratio (CVR) and the content validity index (CVI) were evaluated using the judgment of a panel of experts. Several items whose CVR was less than 0.6 (based on the number of experts) were also eliminated; overlapping components were merged. Based on the results, the number of components was reduced to 42 items, and thus the questionnaire items were 42.

\section{FIGURE 1}

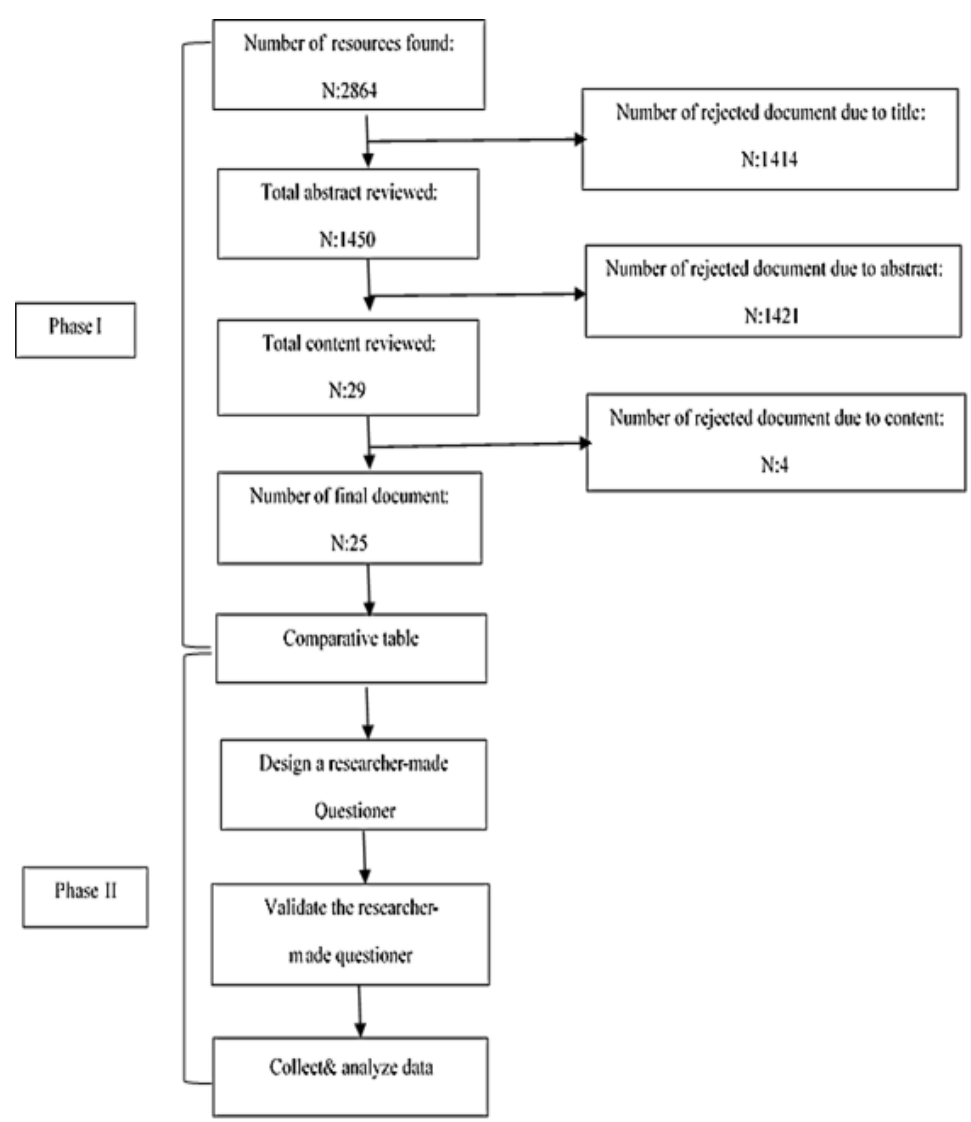

Reliability was examined using the Cronbach's alpha coefficient, first separately for each studied dimension and then for all dimensions. The Cronbach's alpha coefficient was used to examine the reliability of each studied dimension, first separately and then together. Cronbach's alpha coefficient of the questionnaire was obtained at 0.932. The questionnaire items were measured using the Likert 5-point scale 1 = very low, $2=$ low, $3=$ moderate, $4=$ high, and $5=$ very high). 
The statistical population of the study was the managers, chairman and deputies, and experts of contracts and hospital assistance experts, managers and legal experts of the university headquarters, the board of trustees of charities and managers and experts of charity centers. A stratified random method was used for sampling. The statistical sample size was considered using Cochran's formula. The research sample was calculated to be 300 people (Table 1). To complete the number of samples, the possibility of non-cooperation or elimination of nomcompleted questionnaires, 330 questionnaires were distributed. Finally, 300 complete questionnaires were collected. Also, Bartlett and KMO tests were used to examine the adequacy of the sample for each variable in the model and the complete model. Inclusion criteria of the research are the organizational position of individuals and their employment in management departments, medical units and charity institutions.

Demographic data were analyzed using descriptive statistical methods and Kolmogorov-Smirnov test was used to check the normality of data, and Levene's test were used to check the homogeneity of the data. To identify the effective factors, three indices of eigenvalue, ratio of variance explained by each factor and the rotated scree diagram and varimax rotation were used for exploratory factor analysis. Then, to confirm the factors extracted from the questionnaire in the factor analysis stage, confirmatory factor analysis model was used in SPSS 18 and AMOS software. The results provided the suggested purchase management model of hospitals affiliated with Shahid Beheshti University of Medical Sciences.

TABLE 1: SAMPLE RESEARCH SEPARATELY IN EACH CATEGORY

\begin{tabular}{|l|l|l|l|l|l|}
\hline & TARGET POPULATION & $\begin{array}{l}\text { QUANTITY OF TARGET } \\
\text { POPULATION }\end{array}$ & $\begin{array}{l}\text { THE COEFFICIENT OF } \\
\text { DIVISION }\end{array}$ & \multicolumn{2}{|c|}{ SAMPLE RESEARCH } \\
\hline 1 & $\begin{array}{l}\text { the managers, chairman and deputies } \\
\text { of hospital }\end{array}$ & 138 & 0.34 & 90 & 101 \\
\hline 2 & hospital contracts experts & 91 & 0.22 & 60 & 66 \\
\hline 3 & $\begin{array}{l}\text { managers and legal experts of the } \\
\text { university headquarters }\end{array}$ & 30 & 0.07 & 20 & 22 \\
\hline 4 & board of trustees of charities & 24 & 0.06 & 16 & 18 \\
\hline 5 & experts of charity centers & 128 & 0.31 & 84 & 93 \\
\hline \multicolumn{1}{|c|}{ Total } & 411 & 1 & 270 & 300 \\
\hline
\end{tabular}

\section{RESULTS}

Of the 300 participants, 144 (48\%) were male and 156 (52\%) were female. The results showed that the mean (standard deviation) age for women was 39.97 (8.73) and for men was 41.31 (8.39). In addition, women had a somewhat lower median (age) than men. Moreover, the mean (standard deviation) years of service for women and men was 14.34 (7.26) and 11.76 (8.05) years respectively. Overall, the mean and standard deviation of the participants' years of service was 13.00 (7.78) years. Using factor analysis, the questionnaire questions were summarized into few factors to be used for modeling. To examine the exploratory factor analysis, questions 1 to 42 were included in the analysis. Table 2 shows the sampling adequacy criterion test and the Bartlett test. The KMO test measured sampling adequacy of each variable in the model and the complete model; it means that the amount of intra-data variance explained by the factors is acceptable. The null hypothesis of Bartlett test (zero covariance's between factors) is rejected at significance $<0.001$. 
TABLE 2: SAMPLING ADEQUACY STANDARD TEST AND BARTLETT TEST

\begin{tabular}{|c|c|c|c|}
\hline \multirow{2}{*}{ KMO TEST } & \multicolumn{3}{|l|}{ BARTLETI TEST } \\
\hline & CHI-SQUARE STATISTIC & DF & P-VALUE \\
\hline 0.84 & 4361.15 & 703 & $0.001>$ \\
\hline
\end{tabular}

Table 3 (appendix 1) shows the variance explained by the factors. Accordingly, 6 factors accounted for more than $50 \%$ of the total variation of the research variables. In general, seven factors had an eigenvalue of more than 1 (the minimum eigenvalue required to form a factor). The seventh factor didn't change the value of the cumulative variance, so six factors were ultimately selected as the final factors.

In exploratory factor analysis, using the matrix of rotated factors with varimax rotation, it was shown that each factor includes which variables, six factors were finally selected, which confirmed the results of table 3 . After rotation, the factor load matrix showed which variables were included in each factor. Based on the questionnaire, six factors were selected for this research as follows: the selection of supporting organizations, different ways of attracting cooperation, determination of the contract pattern, the share of current and consumption expenditures, determination of capital expenditures, and the selection of hospitalization sections. According to table 3 included in appendix 1, questions 1 to 10 comprised the first factor, questions 15 to 21 the third factor, questions 22 to 30 the fourth factor, questions 31 to 35 the fifth factor, and questions 38 to 42 the sixth factor. Questions 11,13 and 14 had a noticeable presence in the second factor, and due to the similar nature of question 12 to these three questions, it was also categorized in the second factor.

After studying the measurement model and the confirmatory factor analysis, the structural model was examined. This model was estimated after stipulating the parameters of the relationship of the University of Medical Sciences with the methods of attracting the cooperation of supporting organizations to determine the capital contribution. The multivariate normality (Mardia coefficient) was 19.02 indicating that this model was not normal. Therefore, the bootstrap method was used to evaluate the coefficients. The model fit indices are presented shows that the fit indices were desirable in almost all cases and the fit of the model could be considered appropriate and adequate (Table 4, 5).

TABLE 4. STRUCTURAL MODEL FIT INDICES AFTER APPLYING CORRECTION INDICES

\begin{tabular}{|l|l|l|}
\hline INDEX & INDEX VALUE & ACCEPTABLE VALUE \\
\hline CMIN/DF & 1.43 & $<3$ \\
\hline GFI & 0.86 & $>0.8$ \\
\hline AGFI & 0.84 & $>0.8$ \\
\hline CFI & 0.92 & $>0.9$ \\
\hline IFI & 0.92 & $>0.9$ \\
\hline TLI & 0.91 & $>0.9$ \\
\hline RMSEA & 0.04 & $<0.05$ or $<0.08$ \\
\hline
\end{tabular}


TABLE 5. STANDARDIZED PATH COEFFICIENTS AND BOOTSTRAP STRUCTURAL RESEARCH MODEL

\begin{tabular}{|c|c|c|c|c|c|c|}
\hline \multirow[b]{2}{*}{ PARAMETER } & \multirow{2}{*}{$\begin{array}{l}\text { STANDARDIZED } \\
\text { ESTIMATE }\end{array}$} & \multicolumn{5}{|l|}{ BOOTSTRAP } \\
\hline & & $\begin{array}{l}\text { STANDARD } \\
\text { ESTIMATE }\end{array}$ & ESTIMATE & $\begin{array}{l}\text { UPPER } \\
\text { BOUND }\end{array}$ & $\begin{array}{l}\text { LOWER } \\
\text { BOUND }\end{array}$ & SIGNIFICANCE \\
\hline $\begin{array}{l}\text { indicator of selecting } \\
\text { supportive organizations }\end{array}$ & $\begin{array}{l}\text { Universities of } \\
\text { Medical Sciences }\end{array}$ & 0.825 & 1.158 & 2.569 & 0.308 & 0.032 \\
\hline Cooperation method & $\begin{array}{l}\text { Universities of } \\
\text { Medical Sciences }\end{array}$ & 1.000 & 1.000 & 1.000 & 1.000 & - \\
\hline $\begin{array}{l}\text { determining the contract } \\
\text { model }\end{array}$ & $\begin{array}{l}\text { Universities of } \\
\text { Medical Sciences }\end{array}$ & 1.177 & 1.677 & 2.967 & 0.669 & 0.041 \\
\hline $\begin{array}{l}\text { indicators of selecting } \\
\text { inpatient sections }\end{array}$ & $\begin{array}{l}\text { Universities of } \\
\text { Medical Sciences }\end{array}$ & 0.824 & 1.313 & 3.648 & 0.192 & 0.021 \\
\hline $\begin{array}{l}\text { determining the share of } \\
\text { current consumption costs }\end{array}$ & $\begin{array}{l}\text { Universities of } \\
\text { Medical Sciences }\end{array}$ & 0.530 & 0.549 & 1.020 & 0.146 & 0.010 \\
\hline $\begin{array}{l}\text { determining the share of } \\
\text { capital costs }\end{array}$ & $\begin{array}{l}\text { Universities of } \\
\text { Medical Sciences }\end{array}$ & 1.000 & 1.000 & 1.000 & 1.000 & - \\
\hline
\end{tabular}

\section{DISCUSSION}

According to the research findings, in cooperation with support organizations should be considered the dimensions of indicators of selecting a supportive organization, determining the method of cooperation, determining the contract model, determining the share of current consumption costs, the share of capital costs, and indicators of selecting inpatient ward. In the first step, managers of governmental hospitals should select competent charities for transfer health services and departments to cooperate. The right choice of charities with an initial financial capacity and an accounting system and a certificate of good history is very important. Then, will determine the transferable department. Due to the evaluation of the income and cost status of the transferable department, the cost-effectiveness will be evaluated and then contracts are made with charities using the outsourcing cooperation model. It is time to choose the type of contract. According to the research findings, the type of partnership contract can be the most appropriate option. By determining the type of contract, special accuracy must be taken in setting the provisions of the contract. At first, to be determined the department's consumption costs accurately that charities pay these costs in a partnership contract. The most important point is related to the payment of salaries. According to the present study, the best proposal for the transfer is the radiotherapy and oncology, dialysis, and burn departments. With the spread of economic problems and in order to ensure a stable income in the future, this model of cooperation will help governmental hospitals in various crises.

The present study showed that in the First dimension; Indicators of selecting supportive organization with Standard Estimate of 0.825 , the most effective variable is "having a standard accounting system" with a path coefficient of 0.78 , and in contrast, the least effective variable of this dimension is "resources of agency offices and branches should be spent at agency site" with a path coefficient of 0.41 .

This ensures that communities, foundations, and charities operate in accordance with the established plans and policies and that correcting potential deviations require supervision and control. [5] Lack of an integrated and systematic supervisory system for charities has in some cases led to financial abuse and violations. [16] A standard accounting system with financial transparency in the areas of income, expenditures, number of clients and type of 
provided services could, however, prevent such discrepancies in charities. [17] In "The Regulations on Public Aid Collection by Charity Organizations" has also highlighted the establishment of a workgroup (consisting of provincial and local supervisory bodies) that organizes and supervises the activities of charity organizations. [18] Moreover, Article of "the Guidelines on the Establishment and Operation of Branches and Representatives of NGOs" [19] addresses the appointment of an independent auditor for the independent evaluation of the financial and executive performance of charities in different branches and agencies. [20] A charity sponsoring a public hospital is a wholly independent charity with an independent bank account. [21] According to the survey conducted by Global Tolerance Company, about $75 \%$ of the world's people tend to see transparency in governance, business and nonprofit organizations. Public trust is considered one of the most important and vital factors for improving charities and encouraging people to support charities. [22] Much attention should, therefore, be given to forming annual general assemblies in supporting charity organizations, having allocated bank accounts, in which all deposits and withdrawals are made under the name of the supporting organization, having a certificate of good service record, clarifying the amount of the capital of the supporting organization (movable and immovable) and paying all the resources from the offices and branches.

In the Second dimension of determining the type of contract with Standard Estimate of 1.177, the most effective variable was "participation contract with the nongovernmental sector" with a path coefficient of 0.72 , and the least effective variable of this dimension was "contract of purchasing of services from the non-governmental sector" with a path coefficient of 0.41 .

There are 3 types of contract pattern: 1- the contract pattern of purchasing services from the non-governmental sector (using non-governmental capacities by paying per capita of services provided by a governmental organization in accordance with existing laws and regulations), 2- the contract pattern of cooperating with a non-governmental sector (providing non-governmental real and legal persons with units owned by a governmental organization) and 3- the contract pattern of delegating management to a non-governmental sector (delegating the management of governmental organization to qualified real or legal persons, as mentioned in the regulations with the protection of state ownership). [23-24]
Owing to their natural capabilities, NGOs can be very effective if properly managed [14], and the government should strive to attract these organizations. [25]

Different studies have confirmed that governments alone are not able to provide the money they need. Various factors can account for the lack of resources in the government, including limited resources in providing services, inadequate management, time and money inefficiencies and poor quality of services. Given that the quality of services provided by governments is not favorable and that the services of the private sector are very costly and do not meet the necessary social benefits [26], public-private partnership models are the next best alternative. [27] Partnership contracts have also been tested and used in US infrastructural projects and are considered to be the best type of contracts. [28]

In the Third dimension of consumption and current costs with Standard Estimate of 0.530 , the most effective variable was "share of capital costs of purchasing equipment" with a path coefficient of 0.68 and the least effective variable of this dimension was "the share of current costs of legal deductions, tax debts and value added" with a path coefficient of 0.46 .

Funds raised by charities are spent on supplying equipment and consumables, paying the salaries of the charity staff, and paying patients' health care costs. Implementing the health system reform plan positively affected the activities of the related organizations and led to: a) a development of health services 2) financing and allocation of resources 3) the supply of medical equipment and 4) the prevention and promotion of health. [29]

Supporting organizations are in charge of the share of sector costs including administrative supplies, hoteling consumption expenditures, current costs of personnel salary and benefits, patients' support costs, current costs of energy carriers, current costs of equipment maintenance, current costs of legal deductions, tax liabilities and valueadded tax and other liabilities, current costs of advertisement, fundraising and purchase costs of medical consumables.

In the Fourth dimension of share of capital costs with Standard Estimate of 1, the most effective variable was "obtaining the necessary license and purchasing capital equipment" with a path coefficient of 0.73 and the least 
effective variable of this dimension was "physical space development" with a path coefficient of 0.61 .

Charities can cooperate with the Iranian universities of medical sciences in building and expanding the physical space of health care organizations. According to Article 10 of the Adjustment Law of the completion of half-finished projects with the cooperation of charities, executive bodies are authorized to complete their projects on the basis of a memorandum of understanding with charities and their cooperation. [30, 11$]$

Mayo Clinic also operates as a charity training center to fund capital costs, to develop long-term financial models including cash flows and capital expenditures, and to monitor annual operating budgets in a specific structure. [31]

In the Fifth dimension of selecting inpatient ward with Standard Estimate of 0.842 , the most effective variable was "selection of radiotherapy and oncology wards" with a path coefficient of 0.73 , and the least effective variable of this dimension was "selecting other inpatient wards" with a path coefficient of 0.38 .

In their study on charitable donations to AIDS patients with the aim of analyzing the behavior and attitudes of the Canadian population for charitable donations, Don et al showed that despite the cause being a general humanitarian orientation, only a few people were willing to help charities for AIDS [7]; in other words the cause itself is an effective parameter for gaining support. [32-33]

Different methods for gaining cooperation, according to the research results, this factor had a path coefficient of 1.000. In the study of the constituent variables of the methods of attracting cooperation, the most effective variable is "Attracting cooperation as outsourcing" with a path coefficient of 0.296 , and in contrast, the least effective variable of this dimension is "Attracting cooperation in an acquired way" with a path coefficient of 0.149 .

There are 4 types of cooperative methods including: 1) Acquired method (a large firm completely takes over a smaller firm, 2) Outsourcing (one company carries out its activities through other companies and eventually uses their output, 3) Joint venture (two firms, with the same or different shares, share some of their resources and formally establish the third firm with certain purposes), and 4) Co- operation (one firm shares its different resources with other firms to achieve a commongoal). [7]

The most important limitations of this research are as follows: a limited number of aware experts of contract in answering research questions and time-consuming field data collection.

\section{CONCLUSION}

The present study criticizes the Ministry of Health's decision that forces hospitals to establish charities. Hospitals are unable to properly recruit and retain people in these charities. Organizational behavior of governmental employees has shown that busy managers, social workers and other employees are not able to deal appropriately and professionally in such situations. According to the results of this study, it can be stated that providing a specific framework for privatizing the inpatient department, signing a contract with a competent charity (with regards to the financing of capital expenditures, the supply and purchase of medical equipment and the current and consumable costs) and using public hospital credits, can help charities raise more money through public donations. The results of the present research are in line with the Chiesa Model and the World Health Organization.

\section{SUGGESTION FOR FUTURE STUDIES}

Designing a practical model for contracting with charities in the field of health

Investigating the distribution and allocation of charitable resources in the country's health system

Designing a model for maintaining charities in the health system

Designing a financing model for public hospitals

Designing a model for establishing charitable nongovernmental organizations

\section{ACKNOWLEDGEMENTS}

The authors would like to thank the managing director and board of trustee of Behnam Daheshpour Charity. 


\section{CONFLICT OF INTEREST}

The authors had no conflict of interest in the various stages of this research.

\section{FUNDING SOURCES}

This research is part of a doctoral dissertation entitled "Designing a Management Model for Cooperation between Financial Supporting Organizations and University Hospitals of Shahid Beheshti University of Medical Sciences" and this research did not receive any specific funding.

\section{References:}

1. Doshmangir L, Azimzadeh S. A Comparative Study of Health Financing Frameworks, Journal of Health System Research. 2018; 14(2): 289-302.

2. Toghyani $M$, Derakhshan $M$, Nasroallahi K. A Theoretical Model for Preserving the Endowment and Charities in the Third Sector of the Economy with Asymmetric Information, Islamic Economics Studies. 2014;7(1): 153-182.

3. Nasiripour A, Maleki M, Gohari M, Aghababa S, Vahedi M. The Role of Governance in Social Charity Marketing: Focusing on Health, Journal of Health Information Management.2014;1(11): 1-9.

4. Maher a. Measuring Health Sector Performance in National Development Plans" .Social Welfare Quarterly. 2003;2(8) 44-49.

5. mohammadi,A. Evaluation of the performance of NGOs in sponsoring medical expenses of patients in Mashhad University of Medical Sciences. Journal of Mashhad University of Medical Sciences;2019, 5, 6773.

6. Maher A, Ahmadi A M, Shokri Jamnani A. Survey of Different Approaches to Health System Financing in the Selected Countries during the Period 1998-2004 and Introducing New Financing Mechanisms for Iran. QJER; 2008, 8 (1):115-149.

7. Mayo Clinic: Governance and Management Structure. (Approved by Board of Trustees on August 14, 2015).

8. Performance report of the Ministry of Health, Treatment and Medical Education during the year 2019.

9. Horton R. Transparency and Trust in the Charity Sector, University of Cambridge, USA; 2015:23(6): 417-436
10. Shaafiee Nikabadi M, Razaviyan B. Identification and Ranking of Effective Indicators on the loyalty of the Charities in Iranian Charities Using Fuzzy Delphi and Structural Interpretative Equation, Quarterly Journal of Socio Cultural Development Studies.2018;6(3): 1-10.

11. Masoodi poor S, Bagheri Nasr Abadi M. The Prioritizing the Key Issues in the Regulation of the Relationship between the Public Sector and NGOs in the Field of Charities .Public Policy. 2018;4(3): 141-158

12. Nekoei moghadam M, Amiryousefi S, Ghorbani bahabadi Z, Amiresmaili M. Role of Charities in the Health System: a Qualitative Study, J Quall Res Health Sci.2013;2(1): 1-10.

13. Soleymani $M$, Kiyaee $H$. Investigating the Role of Benevolent Activities in Fulfilling Micro Funding Capacities in Iran, Collective Funding, An Appropriate Model for Attracting Good Contributions, The First National Conference on Sustainable Good Studies and Evaluation of Good Affairs in Iran; feb 20; Tehran: Iran: Civilika. Text of the Civil Service Management Joint Parliamentary Inquiry Committee on Civil Service Management Bill.2017; 15(2): $119-130$.

14. World Health Organization. The world health report 2000: health systems: improving performance. World Health Organization. Geneva, Switzerland. 2000;25.

15. Chiesa V. \& Manzini R. Organizing For Technology Collaboration: A Managerial Perspective. R\&D management .1998;28(3):199-212.

16. Bordignon M, Grembi V, Piazza S. Who do you blame in local finance? An analysis of municipal financing in Italy, European Journal of Political Economy.2017; 4(9): 146-163.

17. Jesmani M, Rashid Lamir A, Gharekhani H. Dehghan Ghahfarokhi A. Identifying and Prioritizing Economic and Managerial Barriers for Championship Sport in Zanjan Province, Sport Physiology \& Management Investigation. 2019;10(4): 110-111.

18. Katoziyan $\mathrm{N}$. The evolution of the endowment institution and its future prospects; Comparativehistorical study, Journal of Philosophy \& Theology, 2017; 21 (5): 63-79.

19. Vatankhah S, Maleki M, Tofighi S, Barati O, Rafiee S. The Study of Management Contract Conditions in Healthcare Organizations of Selected Countries, Health Information Management.2012;9(3): 431-442.

20. Mosakhani M, Maniyan A, Ehghaghi A. A Model Collaborative Maturity Assessment in Inter- 
Organizational Networks Case Study: Shabab

Network, Public Management Researches. 2015; 18(3):

157-180.

21. Bromideh A, Rezaei A, Bromand-Rad H, Aarabi N. The Impact of Health System Reform Plan on NGOs's

Activities in Health Sector, Journal of Health Based Research.2017;2(4): 355-368.

22. Aghababa S, Maleki M, Gohari M. Narrative Review of Studies on Charity in Health Care Iran, Hakim Health Systems Research Journal.2015; 17(4): 312-325.

23. Bottiglia R. Competitive Frontiers in P2P Lending Crowdfunding, Crowdfunding for SMEs; 2016:4(9): 61 92.

24. Regulations for charitable donations by public charities; 2017.

25. Nosrati M, Sadeghi H, Abdoli G, Agheli-Kohnehshahri L. Applying Public Private Partnership Investment Model in Health: Assessment of Hospital Readiness in Iran, Journal of Management and Medical Informatics School, 2013;1 (2): 137-128.

26. Nosrati M, Sadeghi H, Abdoli G, Agheli-Kohnehshahri L. Applying Public Private Partnership Investment Model in Health: Assessment of Hospital Readiness in Iran, Journal of Management and Medical Informatics School, 2013;1 (2): 137-128.

27. The BMJ Charity Appeal Christmas 2017 : HelpMédecinsSans Frontières Help Child Refugees Worldwide FEATURE. Published 24 January; 2018.

28. Mosadeghrad A, Tajour M, Ehteshami F. Donors' Participation in Financing Health System of Iran, Hakim Health Systems Research Journal.2019;22(1): 26-42.

29. Yavari V, Yahya M. Exploring How to Improve Charity Monitoring and Monitoring Based on the Transparency Approach, Khaire Mandegar 1st National Conference:Study \& Evaluation of Charity in Iran, Tehran: ALA Charity Foundatio.2017;26(5): 20-21.

30. Bull D, Bagwell S, Nicholls J, Sheil F. Supporting Good Health: The Role Of The Charity Sector NPC, 2014 , 13(6): 129-149.

31. Jessica L. Schleifer, BA. Charity Care, Community Benefits by Hospital Type in Texas. December; 2010.

32. Richter A, Katharina Gollan A. Charity law (Germany), European lawyer Reference; 2012: 14(3): 236-245.

33. Humanitarian Assistance (GHA), Report, 2016. http://www.globalhumanitarianassistance.org/wp-
content/uploads/201506//GHA-Report-2015_Interactive_Online.pdf ,Global 


\section{APPENDIX}

TABLE 3. MATRIX OF ROTATED FACTORS WITH VARIMAX ROTATION

\begin{tabular}{|c|c|c|c|c|c|c|}
\hline \multirow{2}{*}{$\begin{array}{l}\text { QUESTION } \\
\text { NUMBER }\end{array}$} & \multicolumn{6}{|c|}{ FINAL FACTORS } \\
\hline & 1 & 2 & 3 & 4 & 5 & 6 \\
\hline & 0.75 & & & & & \\
\hline & 0.69 & & & & & \\
\hline & 0.76 & & & & & \\
\hline & 0.72 & & & & & \\
\hline & 0.70 & & & & & \\
\hline & 0.70 & & & & & \\
\hline & 0.66 & & & & & \\
\hline & 0.70 & & & & & \\
\hline & 0.79 & & & & & \\
\hline & 0.77 & & & & & \\
\hline & & & & & & 0.70 \\
\hline & & & & & & 0.36 \\
\hline & & & & & & 0.80 \\
\hline & & & & & & 0.67 \\
\hline & & & & & 0.62 & \\
\hline & & & & & 0.74 & \\
\hline & & & & & 0.64 & \\
\hline & & & & & 0.71 & \\
\hline & & & & & 0.72 & \\
\hline & & & & & 0.63 & \\
\hline & & & & & 0.75 & \\
\hline & & 0.61 & & & & \\
\hline & & 0.66 & & & & \\
\hline & & 0.69 & & & & \\
\hline & & 0.65 & & & & \\
\hline & & 0.68 & & & & \\
\hline & & 0.67 & & & & \\
\hline & & 0.63 & & & & \\
\hline & & 0.63 & & & & \\
\hline & & 0.71 & & & & \\
\hline & & & & 0.69 & & \\
\hline & & & & 0.75 & & \\
\hline & & & & 0.72 & & \\
\hline & & & & 0.71 & & \\
\hline & & & & 0.76 & & \\
\hline & & & 0.72 & & & \\
\hline & & & 0.68 & & & \\
\hline & & & 0.67 & & & \\
\hline & & & 0.68 & & & \\
\hline & & & 0.74 & & & \\
\hline & & & 0.62 & & & \\
\hline & & & 0.62 & & & \\
\hline
\end{tabular}

